\title{
Effects of mercury on the arterial blood pressure of anesthetized rats
}

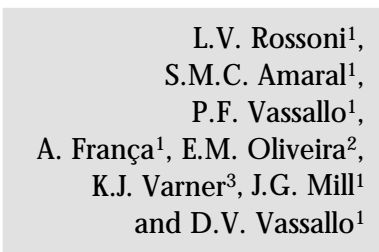

\section{Correspondence}

D.V. Vassallo

Departamento de Ciências

Fisiológicas, CBM/UFES

Av. Marechal Campos, 1468

29040-095 Vitória, ES

Brasil

Fax: +55-27-335-7330

E-mail: daltonv2@ interlink.com.br

Research supported by CNPq (No. 521.552/93-1), FINEP

(No. 66.93.0036.00) and CAPES.

Publication supported by FAPESP.

Received October 19, 1998

Accepted April 5, 1999

\section{Abstract}

The available data suggests that hypotension caused by $\mathrm{Hg}^{2+}$ administration may be produced by a reduction of cardiac contractility or by cholinergic mechanisms. The hemodynamic effects of an intravenous injection of $\mathrm{HgCl}_{2}(5 \mathrm{mg} / \mathrm{kg})$ were studied in anesthetized rats $(\mathrm{N}=12)$ by monitoring left and right ventricular ( $\mathrm{LV}$ and $\mathrm{RV}$ ) systolic and diastolic pressures for $120 \mathrm{~min}$. After $\mathrm{HgCl}_{2}$ administration the LV systolic pressure decreased only after $40 \mathrm{~min}(99 \pm 3.3$ to $85 \pm 8.8$ $\mathrm{mmHg}$ at $80 \mathrm{~min}$ ). However, RV systolic pressure increased, initially slowly but faster after $30 \mathrm{~min}$ ( $25 \pm 1.8$ to $42 \pm 1.6 \mathrm{mmHg}$ at $80 \mathrm{~min}$ ). Both right and left diastolic pressures increased after $\mathrm{HgCl}_{2}$ treatment, suggesting the development of diastolic ventricular dysfunction. Since $\mathrm{HgCl}_{2}$ could be increasing pulmonary vascular resistance, isolated lungs $(\mathrm{N}=10)$ were perfused for 80 min with Krebs solution (continuous flow of $10 \mathrm{ml} / \mathrm{min}$ ) containing or not $5 \mu \mathrm{M} \mathrm{HgCl}_{2}$. A continuous increase in pulmonary vascular resistance was observed, suggesting the direct effect of $\mathrm{Hg}^{2+}$ on the pulmonary vessels $(12 \pm 0.4$ to $29 \pm 3.2$ $\mathrm{mmHg}$ at $30 \mathrm{~min}$ ). To examine the interactions of $\mathrm{Hg}^{2+}$ and changes in cholinergic activity we analyzed the effects of acetylcholine (Ach) on mean arterial blood pressure $(A B P)$ in anesthetized rats $(\mathrm{N}=9)$ before and after $\mathrm{Hg}^{2+}$ treatment $(5 \mathrm{mg} / \mathrm{kg})$. Using the same amount and route used to study the hemodynamic effects we also examined the effects of $\mathrm{Hg}^{2+}$ administration on heart and plasma cholinesterase activity $(\mathrm{N}=$ $10)$. The in vivo hypotensive response to Ach $(0.035$ to $10.5 \mu \mathrm{g})$ was reduced after $\mathrm{Hg}^{2+}$ treatment. Cholinesterase activity $\left(\mu \mathrm{M} \mathrm{h}^{-1} \mathrm{mg}\right.$ protein $^{-1}$ ) increased in heart and plasma (32 and 65\%, respectively) after $\mathrm{Hg}^{2+}$ treatment. In conclusion, the reduction in ABP produced by $\mathrm{Hg}^{2+}$ is not dependent on a putative increase in cholinergic activity. $\mathrm{HgCl}_{2}$ mainly affects cardiac function. The increased pulmonary vascular resistance and cardiac failure due to diastolic dysfunction of both ventricles are factors that might contribute to the reduction of cardiac output and the fall in arterial pressure.

\section{Key words}

- Mercury

- Arterial blood pressure

- Ventricular pressure

- Pulmonary circulation

- Diastolic dysfunction

- Cholinergic activity 


\section{Introduction}

Acute intravenous (iv) administration of $\mathrm{Hg}^{2+}$ produces important hemodynamic changes. The main effect is a progressive decrease of arterial blood pressure (ABP) associated with a reduction of heart rate (HR) $(1,2)$. The mechanisms underlying this hemodynamic alteration are not known. Based on present knowledge, the effects of $\mathrm{Hg}^{2+}$ reducing ABP may result from a reduction in cardiac mechanical activity $(3,4)$, as supported by several findings. Inorganic mercury can produce profound cardiotoxicity (1,3-7). Acute $\mathrm{HgCl}_{2}$ poisoning in Langendorff-perfused rat hearts reduces left ventricular isovolumic systolic pressure and HR and delays atrio-ventricular conduction $(2,3)$. In isolated papillary muscles $1 \mu \mathrm{M} \mathrm{HgCl}_{2}$ increases force and rate of force development but above this concentration force is reduced $(4,7)$. These cardiac effects result from a calcium overload developed as a consequence of the reduction of the sarcolemmal $\mathrm{Na}^{+}, \mathrm{K}^{+}$-ATPase (8-13) and of the sarcoplasmic reticulum (SR) $\mathrm{Ca}^{2+}$-ATPase activities $(6,9,14,15)$. Simultaneous effects of $\mathrm{Hg}^{2+}$ on the $\mathrm{Ca}^{2+}$ channels of the SR also occur, increasing $\mathrm{Ca}^{2+}$ release $(16,17)$. Studies from our laboratory using tetanic contractions of isolated papillary muscles also suggested that a reduction in force might also result from the toxic effects of $\mathrm{HgCl}_{2}$ on the contractile proteins (4). The participation of cholinergic mechanisms was also suggested by results showing that atropine pretreatment blocks the hypotensive effect (2). However, a vasodilatory effect is unlikely since previous reports have suggested that $\mathrm{Hg}^{2+}$ induces vasoconstriction (18).

The present study was performed to examine the hemodynamic changes produced by acute administration of $\mathrm{HgCl}_{2}$. The study was conducted on anesthetized rats by measuring pressure development in both ventricles. We also studied the metal's effects on the isolated perfused vascular bed from the rat lung. To determine whether $\mathrm{Hg}^{2+}$ affects cholinergic mechanisms we analyzed the effects of acetylcholine (Ach) on ABP before and after $\mathrm{Hg}^{2+}$ treatment. In addition, we measured the effects of $\mathrm{Hg}^{2+}$ on heart and plasma pseudocholinesterase activity.

\section{Material and Methods}

\section{General methods}

Studies were performed on 42 Wistar rats (150-330 g) of both sexes. Care and use of laboratory animals were in accordance with established NIH guidelines. All rats had free access to water and were fed rat chow ad libitum.

\section{Experimental protocols}

Hemodynamic effects of $\mathrm{HgCl}_{2}$. Rats were anesthetized with urethane $(1.2 \mathrm{~g} / \mathrm{kg}$, ip $)$ and the carotid artery and jugular and femoral veins were cannulated. The carotid artery and jugular vein cannulas were advanced into the left and right ventricular chambers, respectively, and connected to pressure transducers (Gold P23XL) to measure ventricular pressure (RG-300, FUNBEC). The electrocardiogram was also recorded (ME 100, FUNBEC) with electrodes placed according to the human standard using the D1 lead. The following parameters were analyzed: left ventricular (LV) and right ventricular (RV) systolic and end-diastolic pressures (LVSP, LVDP, RVSP and RVDP, respectively) and HR.

The following protocol was used: acute effects were achieved using an in bolus dose of $\mathrm{HgCl}_{2}$ injected intravenously $(5 \mathrm{mg} / \mathrm{kg}$ ). This dose was selected to provide acute toxic concentrations above $10 \mu \mathrm{g} / \mathrm{ml}$ in blood, considering that the amount injected would be diluted in $40 \mathrm{ml}$ of extracellular fluid per $100 \mathrm{~g}$ of body weight. According to Bakir et al. (19), $5 \mu \mathrm{g} / \mathrm{ml}$ of mercury in the blood causes $28 \%$ of deaths in humans. All ani- 
mals $(\mathrm{N}=7)$ were followed for $120 \mathrm{~min}$ and LV and RV pressures and ECG were recorded before (control condition - C) and at $1,3,5,10,15,20,30,40,50,60,70,80,90$, 100,110 and 120 min after $\mathrm{HgCl}_{2}$ administration. Similar protocols were repeated in control animals $(\mathrm{N}=5)$ without $\mathrm{HgCl}_{2}$ injection.

Lung perfusion. To assess the effects of $\mathrm{Hg}^{2+}$ on lung vascular resistance we perfused rat lungs using a technique similar to that used for the rat tail vascular bed (20). Rats were anesthetized with sodium pentobarbital $(65 \mathrm{mg} / \mathrm{kg}$, ip) and received 500 units of heparin, ip. After 10 min the thorax was opened and a cannula was placed inside the pulmonary artery to perfuse the lungs. The heart and lungs were then excised and placed in a temperature-controlled tissue bath. The heart was not separated from the lungs to avoid lesion of structures. Thus, the nutrient solution was infused through both lungs by the pulmonary artery, returning to the left atria and ventricle. The pulmonary artery was perfused with Krebs-Henseleit (KH) bicarbonate buffer solution, $\mathrm{pH} 7.4$, bubbled with $5 \% \mathrm{CO}_{2}-95 \% \mathrm{O}_{2}(27.2 \mathrm{mM}$ $\mathrm{NaHCO}_{3}, 119 \mathrm{mM} \mathrm{NaCl}, 1 \mathrm{mM} \mathrm{NaH} \mathrm{PO}_{4}$, $1.2 \mathrm{mM} \mathrm{MgSO}_{4}, 2.5 \mathrm{mM} \mathrm{CaCl}_{2} .2 \mathrm{H}_{2} \mathrm{O}, 11$ $\mathrm{mM}$ glucose, $5.4 \mathrm{mM} \mathrm{KCl}$ and $0.03 \mathrm{mM}$ EDTA), at $36 \pm 0.5^{\circ} \mathrm{C}$, using a peristaltic pump at a constant flow of $10 \mathrm{ml} / \mathrm{min}$. The pulmonary perfusion pressure was measured with a TP-200T-Nihon-Kohden pressure transducer (connected to an MP-100 FUNBEC preamplifier) placed between the pump and the arterial cannula and recorded continuously on a polygraphic (ANAMED, AM-820) recorder.

Since lungs appeared to be in good condition indicated by a clear aspect and floating in the tissue bath, after a 10 - to $15-\mathrm{min}$ equilibration period the experimental protocol was initiated. The mean perfusion pressure of the pulmonary artery (PMPP) was measured under control conditions and followed for 50 min during continuous infusion of normal Krebs $(\mathrm{N}=5)$ or Krebs containing $5 \mu \mathrm{M} \mathrm{HgCl}_{2}(1360 \mathrm{ng} / \mathrm{ml})(\mathrm{N}=5)$; PMPP was then measured at $5,10,15,20,30,40$ and $50 \mathrm{~min}$. A similar protocol was repeated in lungs perfused without $\mathrm{HgCl}_{2}$. Since PMPP increased during $\mathrm{Hg}^{2+}$ infusion pulmonary edema occurred which was confirmed by the observation of a shining lung surface and the complete sinking of the lungs into the solution.

Effects of mercury on cholinergic activity. Effects of mercury on cholinergic activity were evaluated using 2 protocols. Protocol 1: effects of $\mathrm{HgCl}_{2}$ on the hypotensive response elicited by Ach. Nine rats were anesthetized with sodium pentobarbital (65 $\mathrm{mg} / \mathrm{kg}, i p$ ) and implanted with arterial and venous cannulae. Increasing doses of Ach $(0.035,0.105,0.35,1.05,3.5$ or $10.5 \mu \mathrm{g})$ were administered $i v$ before and 30 min after $i v$ injection of $\mathrm{HgCl}_{2}(5 \mathrm{mg} / \mathrm{kg})$. The magnitude of the peak decrease in mean blood pressure (MBP) elicited by all doses of Ach was recorded. Protocol 2: effects of $\mathrm{HgCl}_{2}$ on heart and plasma cholinesterase activity. Two groups of rats were anesthetized with pentobarbital and prepared with cannulae as described above. Six rats received an injection of $\mathrm{HgCl}_{2}(5 \mathrm{mg} / \mathrm{kg}, i v)$, while 5 control rats received $i v$ injections of saline. Fifteen minutes after the injections the rats were killed by decapitation and heart and blood samples were collected. The cardiac tissue was immediately homogenized in $0.32 \mathrm{M}$ saccharose plus $10 \mathrm{mM}$ Tris- $\mathrm{HCl}$ solution, $\mathrm{pH} 7.5$ ( $1 \mathrm{~g}$ of tissue per $10 \mathrm{ml}$ of solution) and centrifuged at $1,000 \mathrm{rpm}$ for $10 \mathrm{~min}$. Plasma and tissue pseudocholinesterase activity ( $\mu \mathrm{M} \mathrm{h}^{-1} \mathrm{mg}$ protein ${ }^{-1}$ ) was measured using the method of Ellman et al. (21). Protein was determined by the Coomassie blue method (22) with bovine serum albumin as a standard.

\section{D rugs used}

Ach, $\mathrm{HgCl}_{2}$, urethane and pentobarbital 


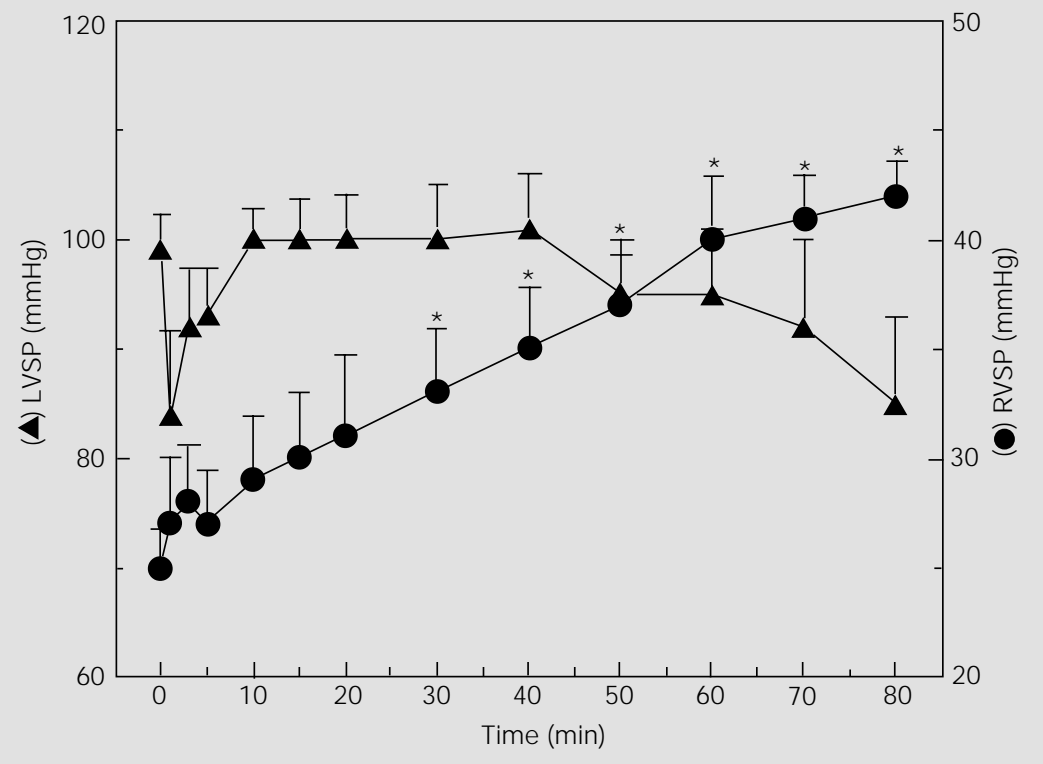

Figure 1 - Effects of $\mathrm{HgCl}_{2}$ on the time course changes of systolic pressure (SP) in the right ventricle (RV) (circles) and left ventricle (LV) (triangles) of anesthetized rats. Zero time is the control condition of the RV or LV systolic pressure obtained before $\mathrm{HgCl}_{2}$ administration (5 $\mathrm{mg} / \mathrm{kg}$ ). Each symbol indicates the mean $\pm \mathrm{SEM} . * \mathrm{P}<0.05$, one-way ANOVA used to compare the time course changes of RV or LV systolic pressure to their respective controls. Observe that there were only minor changes in LV systolic pressure, whereas changes in RV systolic pressure were more significant.

Table 1 - Time course changes of left ventricular (LV), right ventricular (RV), systolic (SP) and diastolic (DP) pressures of untreated rats and pulmonary mean perfusion pressure (PMPP) of untreated isolated perfused lungs.

\begin{tabular}{|c|c|c|c|c|c|}
\hline \multirow[t]{2}{*}{ Time (min) } & \multicolumn{2}{|c|}{ LV } & \multicolumn{2}{|c|}{ RV } & \multirow{2}{*}{$\begin{array}{c}\text { Lungs } \\
\text { PMPP } \\
\text { (mmHg) }\end{array}$} \\
\hline & $\begin{array}{c}\mathrm{SP} \\
(\mathrm{mmHg})\end{array}$ & $\begin{array}{c}\mathrm{DP} \\
(\mathrm{mmHg})\end{array}$ & $\begin{array}{c}\mathrm{SP} \\
(\mathrm{mmHg})\end{array}$ & $\begin{array}{c}\mathrm{DP} \\
(\mathrm{mmHg})\end{array}$ & \\
\hline 0 & $93 \pm 5$ & $4 \pm 1.7$ & $23 \pm 1.0$ & $3 \pm 0.7$ & $19 \pm 0.3$ \\
\hline 1 & $93 \pm 5$ & $5 \pm 1.7$ & $23 \pm 0.6$ & $4 \pm 0.5$ & - \\
\hline 3 & $91 \pm 5$ & $4 \pm 1.6$ & $22 \pm 0.5$ & $3 \pm 0.4$ & - \\
\hline 5 & $92 \pm 5$ & $4 \pm 1.7$ & $22 \pm 0.4$ & $3 \pm 0.4$ & $19 \pm 0.8$ \\
\hline 10 & $91 \pm 5$ & $4 \pm 1.7$ & $23 \pm 1.1$ & $3 \pm 0.4$ & $18 \pm 1.8$ \\
\hline 15 & $91 \pm 4$ & $5 \pm 1.4$ & $22 \pm 0.7$ & $3 \pm 0.25$ & $16 \pm 4.1$ \\
\hline 20 & $90 \pm 5$ & $4 \pm 1.7$ & $22 \pm 0.6$ & $3 \pm 0.4$ & $17 \pm 5.2$ \\
\hline 30 & $92 \pm 5$ & $4 \pm 0.7$ & $22 \pm 0.6$ & $4 \pm 0.9$ & - \\
\hline 40 & $92 \pm 5$ & $4 \pm 0.8$ & $22 \pm 0.9$ & $3 \pm 0.5$ & - \\
\hline 50 & $92 \pm 5$ & $4 \pm 0.5$ & $22 \pm 1.0$ & $3 \pm 0.4$ & $16 \pm 5.5$ \\
\hline 60 & $92 \pm 5$ & $4 \pm 0.4$ & $23 \pm 1.0$ & $3 \pm 0.25$ & - \\
\hline 70 & $92 \pm 4$ & $4 \pm 0.8$ & $22 \pm 1.0$ & $4 \pm 0.25$ & - \\
\hline 80 & $93 \pm 5$ & $4 \pm 0.8$ & $22 \pm 1.0$ & $4 \pm 0.6$ & - \\
\hline
\end{tabular}

were purchased from Sigma Chemical Co., St. Louis, MO; heparin was purchased from Roche Pharmaceuticals, São Paulo, SP, Brazil.

\section{Data analysis}

Data are reported as mean $\pm \mathrm{SEM}$. Comparisons between means were made using a repeated-measures ANOVA or the Student $t$-test. A significant ANOVA was followed by a Tukey test to compare the means. The level of significance was set at $\mathrm{P}<0.05$.

\section{Results}

\section{Hemodynamic studies}

Figure 1 shows that 1 min after $\mathrm{HgCl}_{2}$ iv injection there was a small increase in RVSP and a small decrease in LVSP. RVSP showed minor changes up to the 20th minute while LVSP did not change until the 40th minute. Then RVSP began to increase continuously, attaining an increment of $60 \%$ after $80 \mathrm{~min}$. LVSP tended to decrease attaining a small but significant decrement of $20 \%$ only after $80 \mathrm{~min}$. RVSP and LVSP of control rats did not change throughout the experiment (Table 1). The diastolic pressure of both RV and LV suddenly increased after $\mathrm{HgCl}_{2}$ injection (Figure 2) and showed a continuous tendency to increase thereafter.

\section{Perfused lungs}

Since there was an increase in RV systolic and diastolic pressures after $\mathrm{Hg}^{2+}$ treatment the possibility of a pulmonary vasoconstrictor effect produced by the metal was considered. Isolated lungs were then perfused with a constant flow $(10 \mathrm{ml} / \mathrm{min})$ to investigate this possibility. After the beginning of continuous $\mathrm{HgCl}_{2}$ infusion PMPP increased continuously (Figure 3 ) while no changes were observed in untreated lungs (Table 1). If we plot PMPP and RVSP it can 
be seen that both variables increase in parallel up to 30 min after the beginning of continuous $\mathrm{HgCl}_{2}$ infusion (Figure 3). It is interesting to point out that about this time the PMPP begins to fall and this is coincident with signs of pulmonary edema $(32 \pm 2.9$ $\mathrm{mmHg}$ ). Indeed, signs of pulmonary edema (dyspnea, tachypnea, pulmonary rales) also occurred in anesthetized rats at a not too different RVSP $(41.6 \pm 1.61 \mathrm{mmHg})$. This usually happened $50 \mathrm{~min}$ after the beginning of $\mathrm{HgCl}_{2}$ administration and was followed by intense dyspnea and death of the rats at 80 min.

\section{Effects of mercury on cholinergic activity}

Intravenous administration of Ach elicited dose-related decreases in MBP and HR (Figure 4). Administration of $\mathrm{HgCl}_{2}$ reduced the magnitude of the hypotensive response to all doses of Ach (Figure 4). Regarding heart rate, only at the dose of $3.5 \mu \mathrm{g}$ was the bradycardic response significantly attenuated. All the other bradycardic responses were similar to the pretreatment response.

To determine whether $\mathrm{Hg}^{2+}$ decreased the hypotensive response to Ach by increasing cholinesterase activity we measured the specific activity of cholinesterase in the plasma and heart of $\mathrm{Hg}^{2+}$-treated and salinetreated rats. $\mathrm{Hg}^{2+}$ treatment significantly increased cholinesterase activity in heart and plasma by 32 and $65 \%$, respectively (Table 2).

\section{Discussion}

The present results support the view that the reduction of ABP caused by acute administration of $\mathrm{Hg}^{2+}$ in vivo depends mainly on the depression of cardiac mechanical function. This depression resulted from the development of diastolic dysfunction of both ventricles plus pulmonary hypertension.

Previous reports showed that one of the main cardiovascular changes occurring in

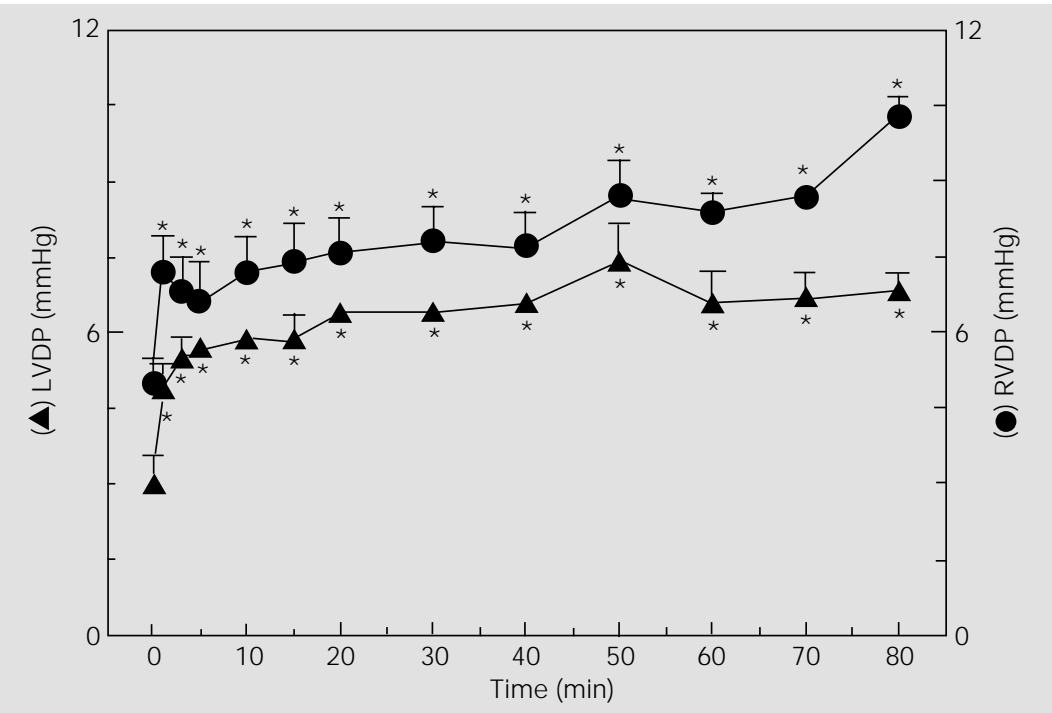

Figure 2 - Effects of $\mathrm{HgCl}_{2}, 5 \mathrm{mg} / \mathrm{kg}$, on the time course changes in diastolic pressures (DP) of the right ventricle (RV) (circles) and left ventricle (LV) (triangles) of anesthetized rats. Zero time is the control condition of the RV or LV diastolic pressure obtained before $\mathrm{HgCl}_{2}$ administration. Each symbol represents the mean $\pm \mathrm{SEM} . * \mathrm{P}<0.05$, one-way ANOVA used to compare the time course changes of RV or LV diastolic pressures to its respective control. Observe that DPs, in contrast to the systolic pressure changes, increased progressively for both ventricular chambers.

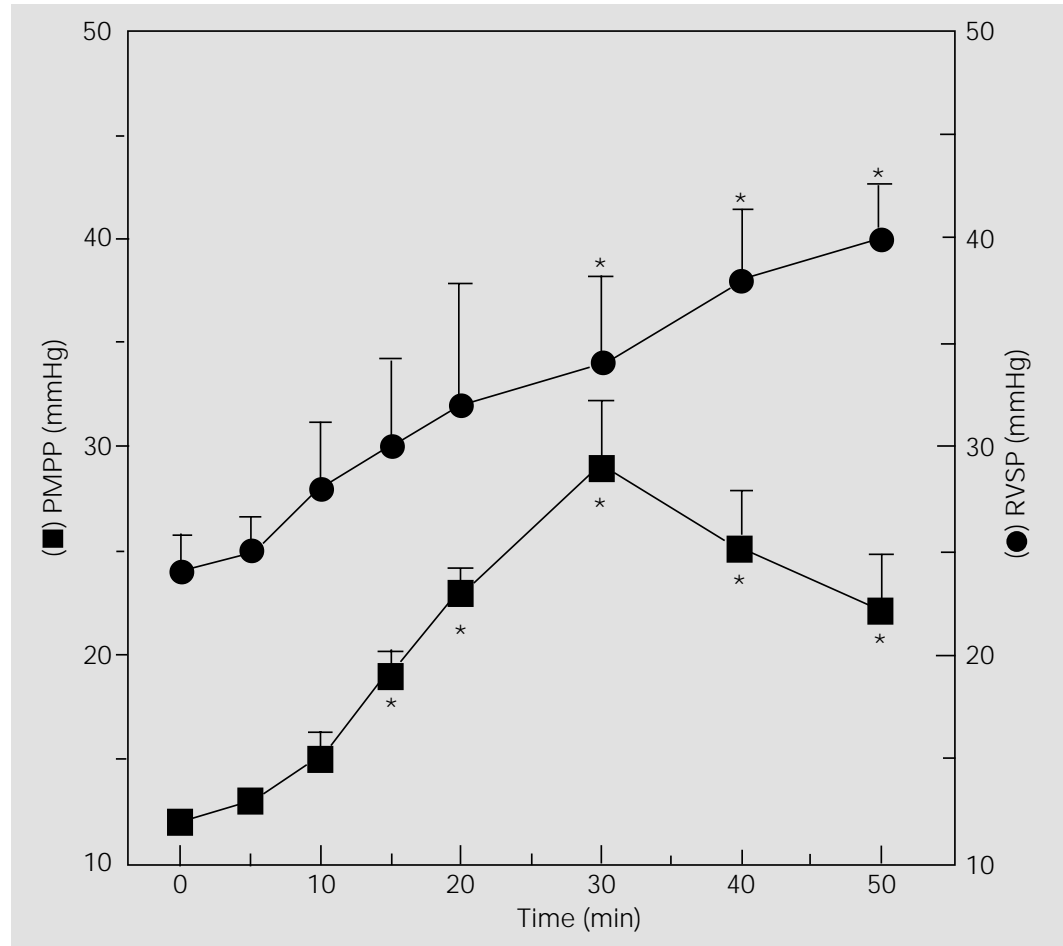

Figure 3 - Simultaneous presentation of the effects of $\mathrm{HgCl}_{2}$ on the time course of right ventricular systolic pressure (RVSP) (circles) of anesthetized rats and the pulmonary mean perfusion pressure (PMPP) (squares) of isolated perfused lungs. Zero time is the control condition of both parameters obtained before $\mathrm{HgCl}_{2}$ administration. Each symbol represents the mean $\pm \mathrm{SEM}$. $* \mathrm{P}<0.05$, one-way ANOVA used to compare the time course changes of RVSP or PMPP to their respective control. 


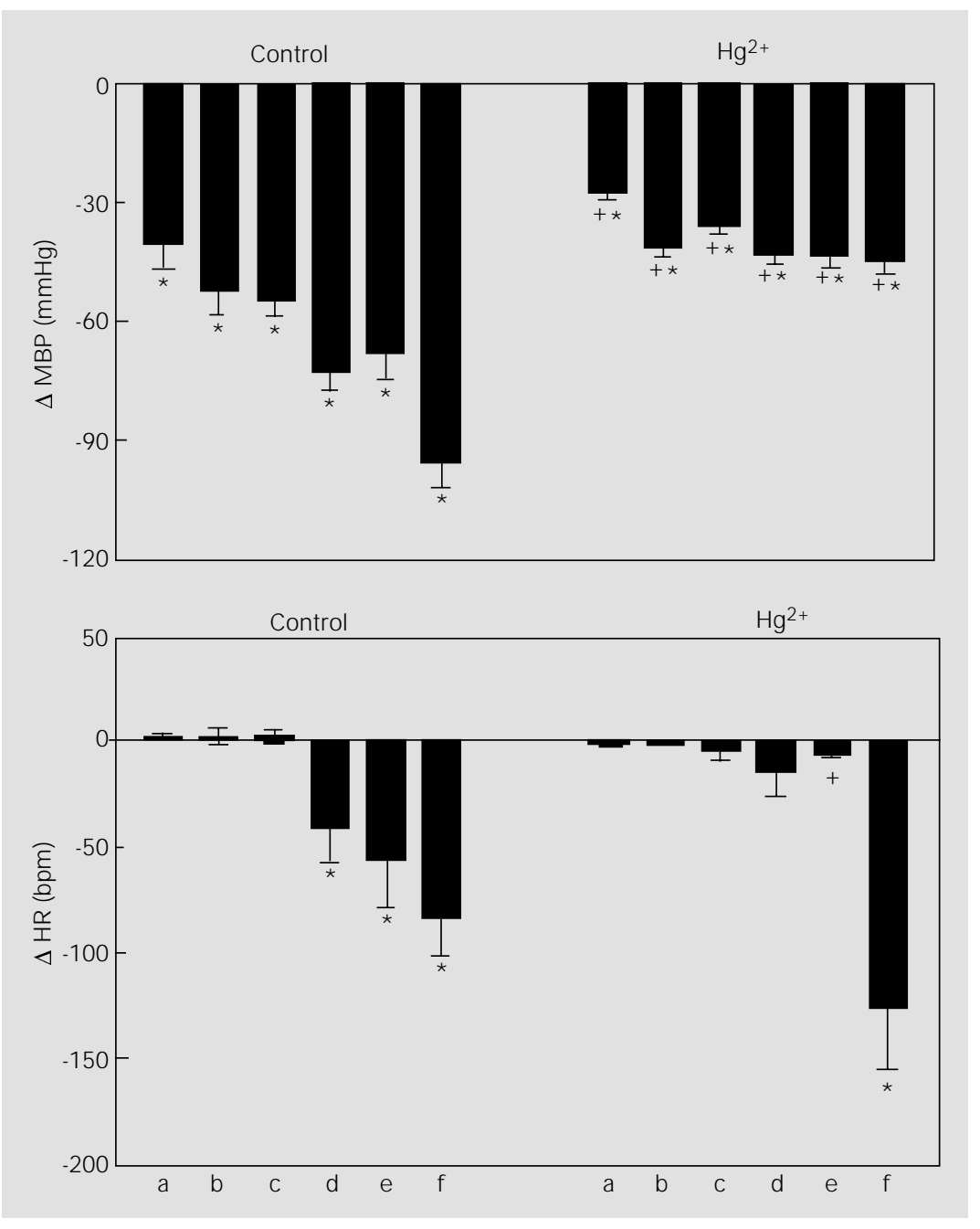

Figure 4 - Effects of increasing concentrations of acetylcholine (Ach) on mean blood pressure (MBP) and heart rate ( $\mathrm{HR}$ ) before (control) and after $\mathrm{HgCl}_{2}\left(\mathrm{Hg}^{2+}\right)$ treatment $(5 \mathrm{mg} /$ $\mathrm{kg})$. a, b, c, d, e and f correspond to increasing concentrations of Ach $(0.035,0.105,0.35$, 1.05, 3.5 and $10.5 \mu \mathrm{g}$, respectively) injected iv. Each column represents the mean and the bars one SEM. Two-way ANOVA indicated a significant decrease in MBP and HR. $* P<0.005$ for Ach vs Ach-free, both before and after $\mathrm{Hg}^{2+}$ treatment and ${ }^{+} \mathrm{P}<0.01$ for differences between each Ach effect before and after $\mathrm{Hg}^{2+}$ treatment.

Table 2 - Cholinesterase activity $\left(\mu \mathrm{M} \mathrm{h} \mathrm{h}^{-1} \mathrm{mg}\right.$ protein $\left.^{-1}\right)$ measured in heart and plasma before (control) and after $\mathrm{HgCl}_{2}$ treatment.

Data are reported as mean \pm SEM. $N=$ Number of experiments. $* \mathrm{P}<0.01$ compared to control (Student t-test).

\begin{tabular}{llll}
\hline & Control & $\mathrm{HgCl}_{2}(5 \mathrm{mg} / \mathrm{kg})$ & \\
\hline Heart & $0.76 \pm 0.04(\mathrm{~N}=5)$ & $1.0 \pm 0.09(\mathrm{~N}=6)^{*}$ & $32 \%$ activation \\
Plasma & $0.23 \pm 0.04(\mathrm{~N}=5)$ & $0.38 \pm 0.07(\mathrm{~N}=6)^{*}$ & $65 \%$ activation
\end{tabular}

response to the acute administration of $\mathrm{Hg}^{2+}$ in vivo was a reduction in $\mathrm{ABP}(1,2)$. The reduction of $A B P$ could result from the deterioration of cardiac mechanical function $(1,2,4,5,7)$ and perhaps interactions of $\mathrm{Hg}^{2+}$ and cholinergic mechanisms could account for the ABP reduction since atropine blocks the $\mathrm{Hg}^{2+}$-induced hypotension (2). The purpose of our study was to determine whether any or all of these possible mechanisms were responsible for the reduction of $\mathrm{ABP}$ caused by $\mathrm{Hg}^{2+}$.

\section{Hemodynamic effects of $\mathbf{H g}^{2+}$}

One of the main mechanisms which may account for the hypotensive response to $\mathrm{Hg}^{2+}$ is a direct effect reducing myocardial performance $(1,2,4,5,7)$. Acute $\mathrm{HgCl}_{2}$ poisoning in Langendorff-perfused rat hearts reduced the left ventricular systolic pressure and heart rate and delayed atrioventricular conduction $(2,3)$. In addition, other studies from our laboratory using tetanic contractions of isolated papillary muscles also suggested that the force reduction could result from the effect of $\mathrm{HgCl}_{2}$ on contractile proteins (4).

Only an important reduction in $\mathrm{ABP}$ was described for acute cardiovascular toxic effects in vivo $(1,2)$. At least two aspects may contribute to this fall in ABP. Firstly, since $\mathrm{Hg}^{2+}$ affects the cardiac contractile activity in isolated preparations the reduction in $\mathrm{ABP}$ observed in vivo could result from an altered mechanical cardiac function. The second could be a depressed vascular smooth muscle contraction produced by $\mathrm{Hg}^{2+}$ which may reduce $\mathrm{ABP}$. This is unlikely since previous findings showed that $\mathrm{Hg}^{2+}$ induces vasoconstriction (18). These observations raised two possibilities to explain the reduction in ABP: cardiac mechanical failure and/or pulmonary hypertension caused by pulmonary vasoconstriction. These questions were investigated by studying the acute effects of the metal in anesthetized rats, measuring LV and RV systolic and diastolic pressures, and 
on the isolated perfused lung.

For the anesthetized rat the results did not show appreciable changes of LVSP during the first $40 \mathrm{~min}$ after $\mathrm{HgCl}_{2}$ administration. Only after this period of time was a small reduction of LVSP observed. The results suggest that this dose of $\mathrm{HgCl}_{2}$, in vivo, does not produce an important depression of LVSP and cannot explain the reduction of ABP, as we observed before (2). In contrast, RVSP increased slowly during the first $30 \mathrm{~min}$ and then more steeply. Results also indicated that $\mathrm{RV}$ pressure development was preserved and the progressive increment of RVSP could be the result of increased pulmonary vascular resistance. $\mathrm{Hg}^{2+}$ has been reported to constrict the rat tail artery (18) and other types of smooth muscle such as guinea pig ileum and vas deferens (23). In guinea pig ileum and vas deferens, $\mathrm{Hg}^{2+}$ increases basal tone at low concentrations $\left(10^{-9}-10^{-8} \mathrm{M}\right)$ by stimulating autonomic neuromuscular transmission. At higher concentrations $\left(10^{-4} \mathrm{M}\right)$, $\mathrm{Hg}^{2+}$ produces smooth muscle contraction by a direct action.

To answer this question, we perfused isolated lungs at constant flow to measure pulmonary resistance. Again, the increase in vascular resistance produced by $\mathrm{HgCl}_{2}$ was demonstrable and this increased pulmonary resistance could explain the fall in ABP by reducing cardiac output. Although this was not the main goal of the present work, this finding deserves additional comments. Magos et al. (24) reported that the lung is an important site in the removal of elemental $\mathrm{Hg}^{2+}$ from the blood stream. According to these authors, after an intravenous dose of elemental $\mathrm{Hg}^{2+}$ dissolved in aqueous buffer 10 to $20 \%$ of the metal may be exhaled. Thereafter, if $\mathrm{Hg}^{2+}$ increases pulmonary vascular resistance, special attention should be given to diagnostic procedures requiring $\mathrm{Hg}^{2+}$ salts, like lung scintigraphy.

Another interesting aspect resulting from $\mathrm{HgCl}_{2}$ administration was the important increase of the RV and LV diastolic pressures.
Two main mechanisms could explain these findings. First, this could result from an increase in the afterload of both ventricles. However, although being true for the RV, since pulmonary resistance increased, this is unlikely for the LV because the afterload for this chamber decreased as its diastolic pressure increased. The second mechanism could explain the increment of diastolic pressure for both ventricular chambers. This could be the result of a calcium overload since $\mathrm{Hg}^{2+}$ reduces the activity of the calcium $(14,15)$ and sodium pumps (8-13) and increases calcium release from SR $(4,16,17)$. The occurrence of a calcium overload may impair relaxation and cardiac filling during diastole, thereafter reducing cardiac output and then ABP.

\section{Effects of $\mathrm{Hg}^{2+}$ on cholinergic activity}

Previous studies using atropine showed that the decrease in MBP elicited by $\mathrm{HgCl}_{2}$ could be attenuated by prior administration of atropine (2). Several reports presented results which suggested interactions between $\mathrm{Hg}^{2+}$ and cholinergic activities. Burg and coworkers (25) suggested that $\mathrm{Hg}^{2+}$ binds to muscarinic receptors in rat brain preparations. Interactions of $\mathrm{HgCl}_{2}$ and $\mathrm{CH}_{3} \mathrm{HgOH}$ with muscarinic receptor subtypes in the rat brain were also described by Castoldi et al. (26). Kostial and Landeka (27) suggested that $\mathrm{Hg}^{2+}$ might stimulate the release of Ach from nerve terminals. Candura et al. (28) presented similar findings which suggested that small concentrations of $\mathrm{Hg}^{2+}$ stimulate cholinergic transmission while high concentrations inhibit it. Inhibition of cholinergic transmission was also reported by Moberg et al. (23). Mercury may also interfere with cholinergic transmission by blocking $\mathrm{Ca}^{2+}$ dependent Ach release and enhancing $\mathrm{Ca}^{2+}$ independent release in nerve terminals (29). These facts could explain why atropine antagonized the effects of $\mathrm{Hg}^{2+}$.

The administration of $\mathrm{HgCl}_{2}$ attenuated, 
instead of enhancing, the hypotensive and bradycardic responses elicited by exogenous Ach. The explanation for these findings was the observation that $\mathrm{Hg}^{2+}$ increased cholinesterase activity in both plasma and heart. The increased activity of the enzyme may have degraded the exogenously administered Ach before it reached the receptor. However, many reports regarding cholinesterase activity suggested that $\mathrm{Hg}^{2+}$ strongly inhibits this enzyme (30-33) instead of activating it. Our results do not permit a clear explanation for this controversy but some results in the literature may help to explain it. Previous reports showed that the effects of $\mathrm{Hg}^{2+}$ on enzyme activities may differ according to the enzyme affected $(34,35)$ and even within the different organs in the same animal (36). Other reports even suggested that acetylcholinesterase or cholinesterase are not affected by $\mathrm{Hg}^{2+}(37,38)$. Another aspect to be considered is the difference between our protocol and others reported in the literature. Ours was an acute in vivo protocol while all others were performed over a longer period of time, usually days, or in vitro. We may speculate that the activity of plasma and heart cholinesterase may increase just after $\mathrm{Hg}^{2+}$ injection and progressively decrease with the continuation of the toxic effects of the metal.

Another explanation for the attenuation of the hypotensive and bradycardic responses to exogenous Ach by $\mathrm{Hg}^{2+}$ may be the impairment of cholinergic transmission. The same explanation is valid for the effects of atropine since atropine may interfere with the interactions between $\mathrm{Hg}^{2+}$ and the muscarinic receptors. However, taken together, these findings indicate that the interactions with cholinergic mechanisms may not be a pivotal mechanism to explain the reduction in $\mathrm{ABP}$ produced by $\mathrm{Hg}^{2+}$.

In summary, our results confirm previous findings showing that acute administration of $\mathrm{Hg}^{2+}$ decreases $\mathrm{ABP}$ in rats. The present results suggest for the first time that $\mathrm{HgCl}_{2}$ may produce cardiac diastolic failure and pulmonary hypertension in vivo, which may be the main mechanism producing the significant $\mathrm{ABP}$ reduction caused by $\mathrm{HgCl}_{2}$.

\section{References}

1. Rhee HM \& Choi BH (1989). Hemodynamic and electrophysiological effects of mercury in intact anesthetized rabbits and in isolated perfused hearts. Experimental and Molecular Pathology, 50: 281-290.

2. Massaroni L, Rossoni LV, Amaral SMC, Stefanon I, Oliveira EM \& Vassallo DV (1995). Haemodynamic and electrophysiological acute toxic effects of mercury in anaesthetized rats and in Langendorff perfused rat hearts. Pharmacological Research, 32: 27-36.

3. Massaroni L, Oliveira EM, Stefanon I \& Vassallo DV (1992). Effects of mercury on the mechanical and electrical activity of the Langendorff-perfused rat heart. Brazilian J ournal of Medical and Biological Research, 25: 861-864.

4. Oliveira EM, Vassallo DV, Sarkis JJF \& Mill J G (1994). Mercury effects on the contractility of isolated heart muscle. Toxicology and Applied Pharmacology, 128: 86-91.
5. Su JY \& Chen WJ (1979). The effects of methylmercury on isolated cardiac tissues. American J ournal of Pathology, 95: 753-764.

6. Halbach S, Schonsteiner $G$, Ebner $F$ \& Reiter M (1981). The effects of p-chloromercuriphenylsulfonic acid (PCMBS) on force of contraction of mammalian myocardium and on ATP hydrolysis by sarcolemmal ATPase. Naunyn-Schmiedeberg's Archives of Pharmacology, 318: 121-129.

7. Halbach S (1990). Mercury compounds: lipophilicity and toxic effects on isolated myocardial tissue. Archives of Toxicology, 64: 315-319.

8. Magour S, Maser H \& Greim H (1987). The effect of mercury chloride and methyl mercury on brain microsomal $\mathrm{Na}^{+}-\mathrm{K}^{+}-$ ATPase after partial delipidisation with lubrol. Pharmacology and Toxicology, 60: 184-186.

9. Ahammad-Sahib KI, Moorthy KS, Cameron
J A \& Desaiah D (1988). Isoproterenol potentiation of methyl mercury effects in vivo on cardiac ATPases and ${ }^{3} \mathrm{H}$-dopamine uptake. Bulletin of Environmental Contamination and Toxicology, 40: 249-254.

10. Chanez C, Flexor MA \& Bourre J M (1989). Effect of organic and inorganic mercury salts on $\mathrm{Na}^{+} \mathrm{K}^{+} \mathrm{ATPase}$ in different cerebral fraction in control and intrauterine growth-retarded rats: alterations induced by serotonin. Neurotoxicology, 10: 699706.

11. Rajanna B, Chetty CS \& Rajanna S (1990). Effect of mercury chloride on the kinetics of cationic and substrate activation of the rat brain microsomal ATPase system. Biochemical Pharmacology, 39: 1935-1940.

12. Anner BM, Moosmayer $M$ \& Imesch $E$ (1992). Mercury blocks the Na-K-ATPase by a ligand-dependent and reversible mechanism. American J ournal of Physiology, 262: F830-F836.

13. Oliveira EM, Rocha JBT \& Sarkis JJF 
(1994). In vitro and in vivo effects of $\mathrm{HgCl}_{2}$ on synaptossomal ATP diphosphohydrolase (EC 3.6.1.5) from cerebral cortex of developing rats. Archives Internationales de Physiologie, de Biochimie et de Biophysique, 102: 97-102.

14. Reddy RS, J inna RR, Uzodinma JE \& Desaiah D (1988). In vitro effect of mercury and cadmium on brain $\mathrm{Ca}^{2+}{ }^{+}$-ATPase of the catfish Ictalurus punctatus. Bulletin of Environmental Contamination and Toxicology, 41: 324-328.

15. Hechtenberg $S \&$ Beyersmann D (1991). Inhibition of sarcoplasmic reticulum $\mathrm{Ca}^{2+}$ ATPase activity by cadmium, lead and mercury. Enzyme, 45: 109-115.

16. Brunder DG, Dettbarn $C \&$ Palade $P$ (1988). Heavy metal-induced $\mathrm{Ca}^{2}+$ release from sarcoplasmic reticulum. J ournal of Biological Chemistry, 263: 18785-18792.

17. Prabhu SD \& Salama G (1990). The heavy metal ions $\mathrm{Ag}^{+}$and $\mathrm{Hg}^{2+}$ trigger calcium release from cardiac sarcoplasmic reticulum. Archives of Biochemistry and Biophysics, 277: 47-55.

18. Souza HP, França AS, Rossoni LV, Amaral SMC \& Vassallo DV (1996). Efeitos do mercúrio sobre a resistência vascular da arteria caudal do rato. Anais da XI Reunião Anual da FESBE, August 21-24, Caxambu. Resumo 05.012, p 59.

19. Bakir F, Damluji SF, Amin-Zaki L, Murtadha M, Khalidi A, Al-Rawi NY, Tikriti S, Dhahir HI, Clarkson TW, Smith JC \& Doherty RA (1973). Methyl mercury poisoning in Iraq. An interuniversity report. Science, 181: 230-241.

20. França AS, Rossoni LV, Amaral SMC \& Vassallo DV (1997). Reactivity of the isolated perfused rat tail vascular bed. Brazilian J ournal of Medical and Biological Research, 30: 891-895.

21. Ellman BL, Courtney KDL, Andres $V \&$ Freatherstone RM (1960). A new and rapid colorimetric determination of acetylcholinesterase activity. Biochemical Pharmacology, 7: 88-95.
22. Bradford MM (1976). A rapid and sensitive method for the quantification of microgram quantities of protein utilizing the principle of protein-dye binding. Analytical Biochemistry, 72: 218-254.

23. Moberg LE, Appelgren B \& Sjostrand NO (1991). Low concentrations of inorganic mercury inhibit in vitro autonomic transmission in the presence of albumin. Acta Odontologica Scandinavica, 49: 351-359.

24. Magos L, Clarkson TW \& Hudson AR (1989). The effects of dose of elemental mercury and first-pass circulation on exhalation and organ distribution of inorganic mercury in rats. Biochimica et Biophysica Acta, 991: 85-89.

25. Burg V, Northington FK \& Shamoo A (1980). Methylmercury inhibition of rat brain muscarinic receptors. Toxicology and Applied Pharmacology, 52: 285-292.

26. Castoldi AF, Candura SM, Costa P, Manzo L \& Costa LG (1996). Interaction of mercury compounds with muscarinic receptor subtypes in the rat brain. Neurotoxicology, 17: 735-741.

27. Kostial K \& Landeka M (1975). The action of mercury ions on the release of acetylcholine from presynaptic nerve endings. Experientia, 31: 834-835.

28. Candura SM, D'Agostino G, Castoldi AF, Messori E, Liuzzi M, Manzo L \& Tonini M (1997). Effects of mercury chloride and methyl mercury on cholinergic neuromuscular transmission in the guinea-pig ileum. Pharmacological Toxicology, 80: 218-224.

29. Abram Z\& Korossy S (1994). Presynaptic and postsynaptic effects of mercury ions on guinea-pig ileum longitudinal muscle strip preparation. Neurochemical Research, 19: 1467-1472.

30. Dieter MP \& Ludke J L (1975). Studies on combined effects of organophosphates and heavy metals in birds. I. Plasma and brain cholinesterase in coturnix quail fed methyl mercury and orally dosed with parathion. Bulletin of Environmental Contamination and Toxicology, 13: 257-262.
31. Suresh A, Sivaramakrishna B, Victoriamma PC \& Radhakrishnaiah K (1992). Comparative study on the inhibition of acetylcholinesterase activity in the freshwater fish Cyprinus carpio by mercury and zinc. Biochemistry International, 26: 367375.

32. Schmidt GH \& Ibrahim NM (1994). Heavy metal content $\left(\mathrm{Hg}^{2+}, \mathrm{Cd}^{2+}, \mathrm{Pb}^{2+}\right)$ in various body parts: its impact on cholinesterase activity and binding glycoproteins in the grasshopper Aiolopus thalassinus adults. Ecotoxicology and Environmental Safety, 29: 148-164.

33. Devi M \& Fingerman M (1995). Inhibition of acetylcholinesterase activity in the central nervous system of red swamp crayfish, Procambarus clarkii, by mercury, cadmium and lead. Bulletin of Environmental Contamination and Toxicology, 55: 746750.

34. Dieter MP (1975). Further studies on the use of enzyme profiles to monitor residue accumulation in wildlife: plasma enzymes in starlings fed graded concentrations of Morsodren, DDE, Aroclor 1254 and malathion. Archives of Environmental Contamination and Toxicology, 3: 142-150.

35. Sastry KV \& Sharma K (1980). Mercury induced haematological and biochemical anomalies in Ophiocephalus (Channa) punctatus. Toxicological Letters, 5: 245249

36. Gill TS, Tewari H \& Pande J (1990). Use of the fish enzyme system in monitoring water quality: effects of mercury on tissue enzymes. Comparative Biochemistry and Physiology C, 97: 287-292.

37. Hastings FL, Lucier GW \& Klein R (1975). Methylmercury-cholinesterase interactions in rats. Environmental Health Perspectives, 12: 127-130.

38. Kobayashi H, Yuyama A, Matsusaka N, Takeno K \& Yanagiya I (1979). Effects of methylmercury chloride on various cholinergic parameters in vitro. J ournal of Toxicological Sciences, 4: 351-362. 